\begin{tabular}{|c|c|c|}
\hline$\Omega$ & & $\equiv$ \\
\hline $\begin{array}{l}\text { Daan Caudri', } \\
\text { Anders Bjerg², }^{1} \\
\text { Neil Saad³, } \\
\text { Tiago Jacinto4,5, } \\
\text { James Chalmers }{ }^{6} \text {, } \\
\text { Georgia Hardavella7,8 }\end{array}$ & $\begin{array}{l}\text { 'Dept of Pediatrics/Respiratory Medicine, Erasmus University, Rotterdam, The Netherlands, } \\
{ }^{2} \text { Krefting Research Centre, University of Gothenburg, Gothenburg, Sweden, } \\
{ }^{3} \text { National Heart and Lung Institute, Imperial College London, London, UK, } \\
{ }^{4} \text { Instituto \& Hospital CUF Porto, Porto, Portugal, } \\
{ }^{5} \text { Centre for research in Health Technologies and Information Systems, Faculty of Medicine, } \\
\text { Porto, Portugal, } \\
{ }^{6} \text { Dept of Respiratory Medicine, Ninewells Hospital and Medical School, Dundee, UK, } \\
{ }^{7} \text { Dept of Respiratory Medicine, King's College Hospital, London, UK, } \\
{ }^{8} \text { Dept of Respiratory Medicine and Allergy, King's College London, London, UK }\end{array}$ & $\begin{array}{l}\text { Georgia Hardavella, Dept of } \\
\text { Respiratory Medicine and } \\
\text { Allergy, King's College London, } \\
\text { London, UK } \\
\text { ㄹ } \\
\text { georgiahardavella@hotmail.com }\end{array}$ \\
\hline
\end{tabular}

\title{
Doing science: how to get credit for your scientific work
}

Everyone deserves to be acknowledged for their efforts and contributions to a shared goal, and getting credit for your scientific work should be part of a natural process and should be fair and straightforward. However, credit cannot be objectively measured despite it having a big influence and, unfortunately, getting appropriate credit can occasionally be both complicated and challenging.

Consider the football highlights during the sports news; it is the player who scores the goal who is given all the credit, while the other supporting players are given less or no credit. Have you ever felt like one of those supporting players? If so, then you may find this article useful.

\section{How do you know you are not getting credit?}

The simplest answer to this question is when people don't recognise or acknowledge the work you have done. If you feel that your effort and contribution is not being appropriately acknowledged, then it is important to establish whether this is just paranoia of a global conspiracy against you, or if there is a genuine concern and your contribution is not being acknowledged for another reason. It should be remembered that, in the highly competitive academic environment, sometimes, these things don't happen by chance.

\section{Some real-life examples}

\section{Publishing}

Preparing manuscripts for publication is perhaps the most obvious example. Has it ever felt that seemingly from orbit, the professor has beamed down their favourite postdoc as the first author of the paper you have spent the past year preparing? Or places themself as the last author, despite another senior colleague contributing significantly to the project? Such examples are easily spotted, but what about last-minute "authors", who are included for old friendship's sake or for increasing the likelihood of publication? The International Committee of Medical Journal Editors (ICMJE) guidelines to roles and responsibilities (www.icmje.org/ recommendations/browse/roles-and-responsibilities/) is an important resource, giving clear indication as to what constitutes authorship and presents possibilities for giving due credit.

Within publishing, there is also the opportunity to be a part of the peer review process. Getting asked to comment or even review a whole paper for your senior can be a fast-track into more reviewing with all its benefits. Just make sure you are credited for your work in the response to the journal's editor.

\section{Presentations}

Credit for work in presentations is less clear than the process in publishing. As early-career researchers, we rarely get invited to the big

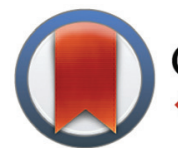

CrossMark

$\leftarrow$ click for updates

Conflict of interest

None declared. 
symposia as speakers, but our professors do; and it is you who is asked to do experiments, conduct analyses, prepare figures or make a few slides for the presentation. Which is all fine, of course, until the work is presented without even a one-slide acknowledgement at the end. Another killer combination is when your boss presents the paper you wrote, which was published with the professor's heir-postdoc as first author, as their publication!

\section{Teaching}

Teaching and supervision is another field where you run the risk of not getting enough credit for your work. The impact is less obvious, but the number of hours spent lecturing, teaching experiments or creating educational material are important criteria for merit for example in university positions. And, while some cosupervisors are forced to fill the void left by an ever-preoccupied main supervisor, others seem to be listed mostly for the sake of their CVs (and for citing their own papers in your thesis). Sometimes, a brave and clever PhD student is in the best position for challenging such inconsistencies and address these issues.

\section{Reasons for not getting credit and its impact}

There can be a number of reasons for not getting credit. It can be down to your own personality, your boss, colleagues or external collaborators.

Your personality can sometimes be a barrier to not getting the appropriate credit. You might not take ownership of your work as you may be too afraid to speak out, or fear being branded as selfish, or perhaps you are just too nice to speak up. Therefore, your supervisor/boss and colleagues might not realise or forget your contribution and could pass you over whenever they are writing a publication or when giving a presentation. Being a timid and quiet team member does not help and can only be very convenient for others to continue getting credit for your work.

Conflict with your boss/colleagues/external collaborators can also be another cause. This could arise through internal competition or because your personality is not compatible with a colleague/your supervisor/external collaborator. The difficulties around this focus on how to stand up against such unfairness.
The consequences of these conflicts can be serious, but not challenging them may be even worse in the long run.

The long run, of course, comes when you notice that your work has been published and your name is not included in the authors' list in the appropriate position, or at all; and this is when things begin to feel awkward. But, as unfortunate as this may feel, it may not be the main problem; you'll begin to see your CV becoming static.

In the current world of science, much revolves around how many papers you have published, in which journals and how many times they were cited. If that's the case, where do you stand if you're not getting any credit for your work? Your professional development will suffer as a result.

In most of the curricular evaluations you will be going through in your career, there will necessarily be an analysis of your scientific productivity. Moreover, when applying for fellowships and grants, one of the main strengths you will have is the research outputs you have produced. The evaluators will most certainly look for prior objective accomplishments in your career when evaluating the proposals. Therefore, not getting credit for your work can have a major impact in your professional development and demands immediate action.

\section{How to get credit}

"Courage and perseverance have a magical talisman, before which difficulties disappear and obstacles vanish into air" John Quincy Adams

As with many things in life, people tend to start thinking about it as soon as the problem hits them. However, in these politically sensitive situations, the longer you wait the more difficult it becomes to resolve matters. The very best way to deal with these situations obviously is to try and avoid them altogether. That is however easier said than done. Nevertheless, there are some ground rules that may help to prevent later problems.

Firstly, it is of vital importance that you take ownership of your work. Do not claim an idea or work that is not your own but make it clear to your peers, supervisor/boss and collaborators which work is yours and that you expect them to acknowledge that. 
Communicating what work you have done or which idea is yours with external collaborators can be more difficult as they do not work or meet with you regularly. However, whenever you are having a meeting to coordinate a project with external collaboration it is good in the end to sum up who has done which part of the work.

Make sure you clearly define what work you have done and clearly document the work you currently do. Whenever discussing ideas make sure to follow-up by keeping a clear record of what is discussed and who has suggested what.

Whenever you give a presentation, do an experiment or give a talk and someone in your group or one of your colleagues uses your data or part of your idea, you should get credit.

It is good to find out what the normal practice at your research department is. Are there general agreements on who is allowed to co-publish on which paper? Try and find out whether this policy is: 1) In line with the codes of conduct in the wider institution; and 2) In line with international ethical standards on publishing. The ICMJE (www.icmje.org) has very clear rules and if your local policy does not comply with them, it is good to bring this up at a very early stage.

It is important to discuss the issue of authorship at a very early stage of the project. Bringing the subject up at an early stage may come across as somewhat possessive or even greedy, but in fact it is not. Getting credit for research is an essential part of each project and is necessary for any sustainable research group. If there are any discrepancies between expectations, the outset is the time to discuss them and, if necessary, change the course of the project. It is essential that all parties are involved in these discussions and that everyone receives a copy of the agreements in writing.

Experience shows that these authorship discussions do not need to be lengthy or even problematic. Again, ICMJE guidelines give a clear framework. Everyone tends to be reasonable when the stakes are not too high. If on the other hand you wait until your paper is ready to be submitted to Nature, the atmosphere of the discussion could change considerably.

Furthermore, you will find that all projects will inevitably change to some extent along the way. New colleagues may join the group, collaborations may be created and the scope of the research may change. This flexibility is essential to performing good and successful research, but it can complicate authorship matters considerably. Avoid talking about authorships all the time, but as soon as a decision is made that affects authorships, it is wise to bring this up. Likewise, before beginning to write the final manuscript, it is wise to again confirm previous agreements on authorship and order.

Research work should always be goal directed, experiments are not performed for the sake of it, and so where possible you should be clear from the outset how your contribution will fit into the wider work of the lab and therefore where in the author list you can expect to find yourself. Also be clear with your supervisor about your own expectations; your supervisor may not know that you want or expect to be the first author of a manuscript unless you tell them.

\section{What next?}

Dealing with workplace conflicts was the topic of the last Doing Science article and many of the same principles apply to resolving conflicts around authorship and credit. As with many aspects of medicine, prevention is always better than cure; however, frank discussions with your supervisor or colleagues are strongly indicated and are more fruitful if you attend these conversations with a clear list of everyone's work and timeline of contributions to the work under dispute.

Science is a team sport, and good relations within scientific teams are essential if the team is to be productive and successful. Supervisors invest a great deal of time in designing studies, gaining research funding and directing the research. They will understandably feel a great deal of ownership over the work, even if the physical experiments or recruitment were performed by you. Sharing credit for work is a two way street, and you also have a responsibility to share credit for work with others who have helped you along the way.

Everyone wants their work to be appreciated and disputes around authorship, credit and acknowledgement can occasionally happen. Avoiding disputes through good communication within teams and maintaining those key relationships is always likely to be better in the long run. 